\title{
Effects of skin on bias and reproducibility of near- infrared spectroscopy measurement of cerebral oxygenation changes in porcine brain
}

\author{
John H. G. M. Klaessens \\ Jeroen C. W. Hopman \\ Radboud University Nijmegen Medical Centre \\ Department of Pediatrics \\ Clinical Physics \\ Nijmegen, The Netherlands \\ E-mail: j.Klaessens@cukz.umcn.nl
}

\section{K. Djien Liem}

Radboud University Nijmegen Medical Centre Department of Pediatrics

Neonatology

Nijmegen, The Netherlands

\section{Sandra H. G. van Os}

Radboud University Nijmegen Medical Centre Department of Pediatrics

Neonatology

Nijmegen, The Netherlands

\section{Johan M. Thijssen}

Radboud University Nijmegen Medical Centre Department of Pediatrics

Clinical Physics

Nijmegen, The Netherlands

\begin{abstract}
The influence of skin on the bias and reproducibility of regional cerebral oxygenation measurements is investigated using $\mathrm{cW}$ near-infrared spectroscopy (NIRS). Receiving optodes are placed over the left and right hemispheres of a piglet $\left(\mathrm{C}_{3}, \mathrm{C}_{4}\right.$ EEG placement code) and one transmitting optode centrally $\left(\mathrm{C}_{z}\right.$ position). Optical densities (OD) are measured during stable normo, mild, and deep hypoxemia. This is done for skin condition 1: all optodes on the skin; skin condition 2: transmitting optode on the skin and one receiving optode on the skull; and skin condition 3: all optodes on the skull. Absolute changes of oxy- $\left(\mathrm{CO}_{2} \mathrm{Hb}\right)$, deoxyhemoglobin $(\mathrm{cHHb})$, and total hemoglobin $(\mathrm{ctHb})$ concentrations $[\mu \mathrm{mol} / \mathrm{L}]$ are calculated from the ODs. These absolute changes are calculated for each skin condition with respect to normoxic condition. Additionally, for skin condition 2, the difference of concentration changes between receiver 1 (skull) and receiver 2 (skin) is calculated. The effect of skin removal is an average increase of attenuation changes by a factor of 1.66 $(=0.51 \mathrm{OD})$ and of the concentration changes due to the arterial oxygen saturation steps by $23 \%$. We conclude that skin significantly influences regional oxygenation measurements. Nevertheless, it is hypothesized that the estimated concentration changes are dominated by changes of the oxygenation in the brain. $\odot 2005$ Society of Photo-Optical Instrumentation Engineers. [DOI: 10.1117/1.1989315]
\end{abstract}

Keywords: brain; hypoxia; near infrared; skin; spectroscopy.

Paper 04181RR received Sep. 17, 2004; revised manuscript received Feb. 21, 2005; accepted for publication Mar. 15, 2005; published online Jul. 22, 2005.

\section{Introduction}

Near-infrared spectroscopy (NIRS) was introduced more than 25 years ago $^{1}$ and this technique has been used in many physiological and clinical studies. Applications were found in monitoring of oxygenation in muscle, ${ }^{2}$ and adult $^{3-5}$ and neonatal ${ }^{6,7}$ brain. A further application is the estimation of cerebral blood volume (CBV). Wyatt et al. ${ }^{8}$ combined NIRS assessment of absolute changes of concentration of oxy- and deoxyhemoglobin $\left(\Delta c \mathrm{O}_{2} \mathrm{Hb}\right.$ and $\Delta c \mathrm{HHb}$, respectively) with measurement of arterial oxygen saturation $\left(\mathrm{SaO}_{2}\right)$ to calculate the $\mathrm{CBV}$ in newborn infants. Cerebral blood flow (CBF) can be measured with NIRS using a bolus of $c \mathrm{O}_{2} \mathrm{Hb}$ as a tracer. ${ }^{9,10}$ Other groups performed NIRS measurement of absorption changes after intravenous injection of a bolus of indocyanine green (ICG) to obtain $\mathrm{CBV}^{11}$ and $\mathrm{CBF} .{ }^{12}$

The question has been raised to what extent superficialcerebral measurement of cerebral Hb-concentrations is influenced by absorption and scattering in external tissue layers, i.e., skin, skull, dura, and cerebro spinal fluid.

Address all correspondence to John Klaessens, 435 Pediatrics, Radboud University Nijmegen Medical Centre, P.O. Box 9101, Nijmegen, Gelderland NL-6500 HB Netherlands. Tel: +31-24-3619063. Fax: +31-24-3616428. E-mail: j.klaessens@cukz.umcn.nl
Hiraoka et al. ${ }^{13}$ performed a simulation study with a layered model of the head. They concluded that for piglets, the contribution of superficial (extra cerebral) layers to the effective path length ranged from 60 to $25 \%$ when changing the optode separation angle from 30 to $75 \mathrm{deg}$.

Okada, Firbank, and Delpy ${ }^{14}$ concluded from a simulation study that in the adult head, NIRS measures mainly oxygenation changes in the superficial brain layers, i.e., within the gray matter, at optode separations between 30 and $90 \mathrm{deg}$. The base for this conclusion was the similar $\mu$ values (transport scattering coefficient) in scalp and skull as well as in gray matter.

There is clear evidence of an "optical channeling" effect by extra cerebral layers in the adult human. ${ }^{15}$ These authors found a significant decrease of light passage, at optode separation of $4 \mathrm{~cm}$, if skin, skull, and dura/cerebrospinal fluid (CSF) were removed. The light attenuation is defined as the negative natural logarithm of the light transmission: $-\ln (T)$. They found an apparent light attenuation of $0.30,1.35$, and $1.51 \mathrm{OD}$, respectively, in successive removal of these layers for one optode. These results might indicate that only $3 \%$ of the optical path passes through the cerebral cortex and 97\%

1083-3668/2005/10(4)/044003/7/\$22.00 @ 2005 SPIE 
through the superficial layers. This conclusion is supported by the simulation studies of Okada et al. ${ }^{16,17}$

A somewhat different approach for assessing the influence of superficial layers on NIRS measurement was followed by Smielewski et al. ${ }^{18,19}$ These authors made a simultaneous measurement of the blood flow velocity in the middle cerebral artery with ultrasound transcranial Doppler (TCD), and of the skin blood flow velocity with laser Doppler flowmetry (LDF). They concluded that NIRS-monitored cerebral oxygenation changes during $\mathrm{CO}_{2}$ reactivity tests were statistically not significantly correlated with skin perfusion. On the other hand, high correlations were observed between NIRS $c \mathrm{O}_{2} \mathrm{Hb}$ concentration changes and end-tidal $\mathrm{CO}_{2}$ and arterial blood flow velocity. Finally, by compression of the superficial temporal artery, it could be concluded that the skin blood flow contribution to the $c \mathrm{O}_{2} \mathrm{Hb}$ reactivity measured with NIRS was approximately $16 \%$.

Although this latter result might lower the concerns about the influence of skin on NIRS measurements of Hb concentration changes in the cerebral cortex, it is still not clear how far the large channeling effects are producing a bias, and whether these effects are wavelength dependent or not. A further question we need to answer is: what contribution do these effects have on the bias and reproducibility of NIRS measurements of $\mathrm{Hb}$ concentration changes? A preliminary report about the present study, in which a correction for the skin on concentration changes was investigated, has been published. ${ }^{20}$

The aim of this animal study was to investigate the influence of the skin on regional cerebral oxygenation measurements. Furthermore, the inter- and intra-individual variability of the measurements was investigated.

\section{Near-Infrared Spectroscopy}

The principle of near-infrared spectroscopy (NIRS) was first described in 1977. ${ }^{1}$ NIRS in tissue is based on measurement of light attenuation caused by absorption and scattering. Tissues are transparent only in a small wavelength range (700 to $1000 \mathrm{~nm}$ ). In this near-infrared region, penetration depths up to $8 \mathrm{~cm}$ can be achieved. ${ }^{21}$

The absorption mechanism can be separated in two parts: one due to chromophores with a constant tissue concentration, and one due to chromophores with a variable concentration. In cerebral tissue, the main varying components are the concentrations of oxy- and deoxyhemoglobin $\left(c \mathrm{O}_{2} \mathrm{Hb}\right.$ and $c \mathrm{HHb}$ ) hemoglobin. The $c \mathrm{O}_{2} \mathrm{Hb}$ and $c \mathrm{HHb}$ in cerebral tissue depend on the hemoglobin oxygen saturation and the cerebral blood volume (CBV). Other absorbers are assumed to be independent of hemoglobin oxygen saturation.

When there is no scattering, the absorption can be described by the Lambert-Beer law.

$$
a(\lambda)=\varepsilon(\lambda) \cdot c \cdot l_{s d}(\lambda),
$$

where $a(\lambda)$ is the measured absorbance $(-) ; \varepsilon(\lambda)$ is the molar extinction coefficient $\left(\mu \mathrm{mol}^{-1} \cdot \mathrm{L} \cdot \mathrm{cm}^{-1}\right) ; c$ is the concentration of the molecules $\left(\mu \mathrm{mol} \cdot \mathrm{L}^{-1}\right)$; and $l_{\mathrm{sd}}(\lambda)$ is the sourcedetector distance $(\mathrm{cm})$.

Scattering effects were incorporated in Eq. (1) by introducing an extra pathlength factor, which results in the modified Lambert-Beer equation. ${ }^{22-25}$ This pathlength factor incorpo- rates the scattering contribution to the overall pathlength of the photons traveling from source to detector. Furthermore, an extra term $R$ was introduced to incorporate oxygenation independent absorption and scattering losses. In matrix notation, Eq. (1) now becomes:

$$
\overline{\mathbf{A}}(\lambda)=\overline{\bar{\varepsilon}}(\lambda) \cdot \overline{\mathbf{c}} \cdot D P F \cdot l_{s d}+\overline{\mathbf{R}}
$$

where $\overline{\mathbf{A}}(\lambda)$ is attenuation; DPF is the differential path length factor; and $\overline{\mathbf{R}}$ is the oxygen independent attenuation.

Several research groups have measured molar extinction coefficients. In this work, the modified Keele matrix ${ }^{22,26}$ was used. The photons arriving at the receiving optode have mainly traveled through a banana-shaped volume spanning from the transmitting to the receiving optode. The size and depth range of this volume can be manipulated by the positioning of the optodes. ${ }^{27-29}$

When comparing two different conditions of the medium, the change of attenuation (i.e., $\Delta \bar{A}$ ) can be related to changes in the concentration of a chromophore (or in the extinction coefficient):

$$
\Delta \overline{\mathbf{A}}=\overline{\bar{\varepsilon}}(\lambda) \cdot \Delta \overline{\mathbf{c}} \cdot D P F \cdot l_{s d} .
$$

Hence, as can be seen in Eq. (3), the scattering term $\bar{R}$ disappears after taking the difference of two conditions. This procedure is normally used in NIRS studies.

In this article, we calculate the concentration change $(\stackrel{\circ}{)}$ with respect to the $\mathrm{SaO}_{2}=100 \%$ level:

$$
\Delta \overline{\mathbf{c}}=\frac{\overline{\bar{\varepsilon}}^{-1}(\lambda) \cdot \Delta \overline{\mathbf{A}}(\lambda)}{D P F \cdot l_{s d}},
$$

where $\Delta$ is the difference relative to $\mathrm{SaO}_{2}=100 \%$ measurement.

The effect of the skin removal was calculated by taking the difference $(d)$ between these concentration changes measured without and with skin (skin condition 2: area 1 minus area 2). The difference was calculated only for the simultaneous measurements to avoid errors caused by small differences in the physiological condition of the animals. In this case, the DPF of both conditions might be different [Eq. (5)].

$$
d \Delta \overline{\mathbf{c}}=\frac{\bar{\varepsilon}^{-1}(\lambda)}{l_{s d}} \cdot\left(\frac{\Delta \overline{\mathbf{A}}_{2}}{D P F_{2}}-\frac{\Delta \overline{\mathbf{A}}}{D P F_{1}}\right),
$$

where $d$ is the difference of $\Delta c$ between area 1 and $2 ; \Delta$ is the difference relative to $\mathrm{SaO}_{2}=100 \%$ measurement; and 1,2 are areas 1 and 2.

Since the authors do not have any data about the effect of skin removal on the DPF, it was necessary to take a fixed value of DPF (4.2) into account. For this reason, any DPF changes become apparent as changes of the attenuation and are translated into apparent changes of concentration.

\section{Materials and Methods}

\subsection{Materials}

The brain of a two week old piglet was selected as a model for the infant brain. ${ }^{30}$ The size of the head (skull thickness, 
circumference) is nearly the same for newborns and piglets, which is important for near-infrared spectroscopy (NIRS) measurement (comparable optode distances $\left.{ }^{28}\right)$. Piglets $(n=3$, age 2 to 3 weeks, weight 7.8 to $9.3 \mathrm{~kg}$ ) were anesthetized, paralyzed, and mechanically ventilated according to the rules of Good Laboratory Practice. The Ethical Committee on Animal Research of the Radboud University Medical Centre Nijmegen approved the experimental and surgical procedures.

The preparation of the piglets has been described earlier. ${ }^{31}$ It was started with intramuscular midazolam $(0.15 \mathrm{mg} / \mathrm{kg})$ as premedication. After $30 \mathrm{~min}$, anesthesia was introduced by intravenous atropine $(0.25 \mathrm{mg})$ and fentanyl $(0.1 \mathrm{mg} / \mathrm{kg})$.

Orotracheal intubation was performed and the animal was put on the ventilator (Babylog 8000, Dräger, Lübeck, Germany). The ventilator settings were adjusted to maintain normoxemia $\left(\mathrm{SaO}_{2}=95\right.$ to $100 \%$ and $\mathrm{paO}_{2}=10$ to $\left.15 \mathrm{kPa}\right)$ and normocapnia $\left(\mathrm{paCO}_{2}=4.5\right.$ to $\left.5.5 \mathrm{kPa}\right)$. During the experiment, anesthesia was maintained with intravenous midazolam $(0.4 \mathrm{mg} / \mathrm{kg} / \mathrm{h})$, pancuronium $(0.1 \mathrm{mg} / \mathrm{kg} / \mathrm{h})$, and fentanyl (0.1 mg/kg/h).

$\mathrm{O}_{2}$ and $\mathrm{CO}_{2}$ waves (i.e., partial pressure versus time) were obtained from a standard monitor (Datex-Capnomac Ultima, Datex-Ohmeda BV, Hoevelaken, The Netherlands) by continuously sampling from the respiratory tubing. A polyvinyl catheter $(2.1 \mathrm{~mm}$ diam) was placed in the abdominal aorta through the left femoral artery for measuring the arterial blood pressure (disposable transducers, Edwards Life Science BV, Los Angeles, California) and for arterial blood gas sampling. The physiological measurements [ECG, rectal temperature, arterial blood pressure, arterial oxygen saturation $\left(\mathrm{SaO}_{2}\right), \mathrm{O}_{2}$ wave, and $\mathrm{CO}_{2}$ wave] were continuously recorded with a computer system and stored for further analysis. Arterial blood samples were analyzed on site with a blood gas analyzer (ABL 510, Radiometer Medical A/S, Copenhagen, Denmark) for the following data: $\mathrm{pH}, \mathrm{pCO}_{2}[\mathrm{kPa}], \mathrm{pO}_{2}[\mathrm{kPa}]$, $\mathrm{cHb}[\mathrm{g} / \mathrm{dl}]$, and $\mathrm{SaO}_{2}[\%]$.

\subsection{Design of the Experiment}

During the experiments, the arterial oxygen saturation $\left(\mathrm{SaO}_{2}\right)$ was changed from normoxia $\left(\mathrm{SaO}_{2}=100 \%\right)$, to mild hypoxia $\left(\mathrm{SaO}_{2}=80 \%\right)$, to severe hypoxia $\left(\mathrm{SaO}_{2}=60 \%\right)$, and back to normoxia. This was achieved by lowering the $\mathrm{FiO}_{2}$ by adding $\mathrm{N}_{2}$ to the inspired gasses. The hypoxia conditions were maintained for at least $10 \mathrm{~min}$ to reach a stable condition. At the end of each stabilizing period an arterial blood sample was taken.

The NIRS instrument used (OYMON) in the experiments was developed at the Instrumentation Department of the Radboud University Medical Centre Nijmegen (Nijmegen, The Netherlands). ${ }^{32}$ The equipment contains laser diodes operated in pulsed mode (pulse length $100 \mathrm{~ns}$ ) at three wavelengths $(767,850$, and $905 \mathrm{~nm})$ and a receiver equipped with an avalanche photodiode. Pulse repetition rate was $1 \mathrm{kHz}$ per wavelength and the processed signal consisted of the consecutive means over 100 pulses, resulting in an effective $10-\mathrm{Hz}$ sampling rate for each wavelength. All the NIRS data were continuously stored on a PC for off-line analysis. The estimated optical densities (OD) correspond to the light absorption between the transmitting and receiving fibers. After changing the $\mathrm{SaO}_{2}$ levels, we waited until a new steady state was es-

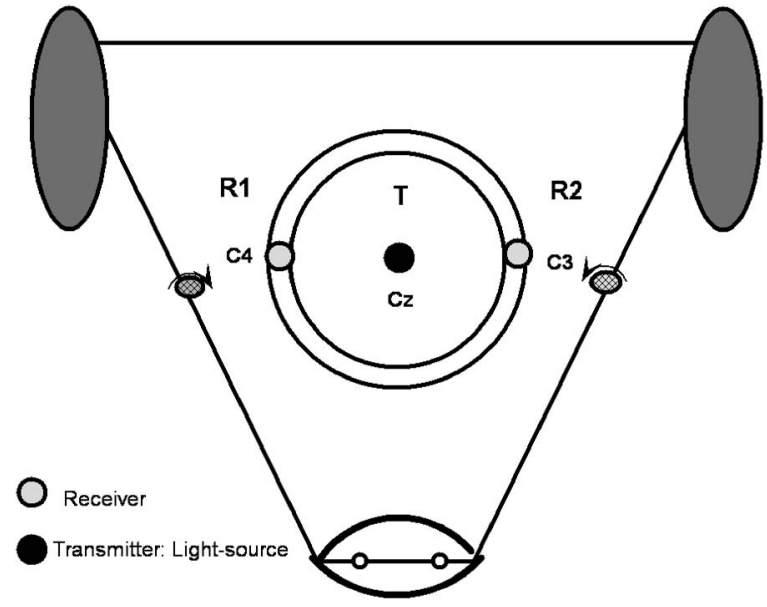

Fig. 1 Scheme of the optode positions on the piglet head. The measurements were done over two areas: area $1=C_{z}-C_{3}$ and area 2 $=C_{z}-C_{4}$. In the present experiments, the skin was only removed directly under the fiber connectors $(\sim 1 \mathrm{~cm}$ diam $)$ and the skull remained intact.

tablished and one minute periods of stable OD signals were selected for further analysis.

After the measured ODs were averaged over a period of one minute, the difference $(\Delta)$ between the concentrations at $\mathrm{SaO}_{2}$ levels 80 and $60 \%$ and those obtained at $\mathrm{SaO}_{2}$ of $100 \%$ were calculated by using Eq. (4).

The optodes were attached to specially constructed holders that were firmly glued with collodion, a glue commonly used to attach EEG electrodes, directly on the skin or skull of the head of the piglet. ${ }^{33}$ Receiving optodes were placed over the left $($ area $=1)$ and right $($ area $=2)$ hemisphere $\left(C_{3}, C_{4}\right.$ EEG placement code) and the transmitting optode on $\mathrm{C}_{z}$ position (Fig. 1). In this optode configuration, we always have two simultaneous measurements, i.e., over the left and right hemisphere. Optical densities (OD) were measured during stable normo-, mild-, and severe hypoxemia $\left(\mathrm{SaO}_{2}=100,80\right.$, and $60 \%$ ) and the average ODs were calculated over a one-minute period, which was interactively selected during off-line analysis of the NIRS data. To study the reproducibility, the measurements were repeated after the receiving optodes were switched from position $\left(\mathrm{C}_{3} \mathrm{C}_{4}\right.$ to $\left.\mathrm{C}_{4} \mathrm{C}_{3}\right)$, and after they were placed back at the starting position. For the three $\mathrm{SaO}_{2}$ levels these measurements were repeated, and after returning to normoxia, two control measurements were done. This whole procedure was repeated for each of the three skin conditions (see also Fig. 2): all optodes with skin (condition 1, skin-skin); one receiving optode directly on the skull, second receiving optode and transmitting optode on the skin (condition 2); transmitting and receiving optodes on the skull (condition 3, skullskull). A total of 196 measurements were performed (3 piglets $\times 3$ skin conditions $\times 3 \quad \mathrm{SaO}_{2}$ levels $\times 3$ repeated measurements $\times 2$ simultaneous areas +3 piglets $\times 3$ skin conditions $\times 2$ repeated measurements $\times 2$ simultaneous areas).

From the ODs at the three wavelengths $(767,850$, and $905 \mathrm{~nm})$, the absolute concentration changes $\Delta c \mathrm{O}_{2} \mathrm{Hb}$, $\Delta c \mathrm{HHb}$, and $\Delta c \mathrm{tHb}(\mu \mathrm{mol} / \mathrm{L})$ were calculated using the modified Lambert-Beer law [Eq. (3)]. 


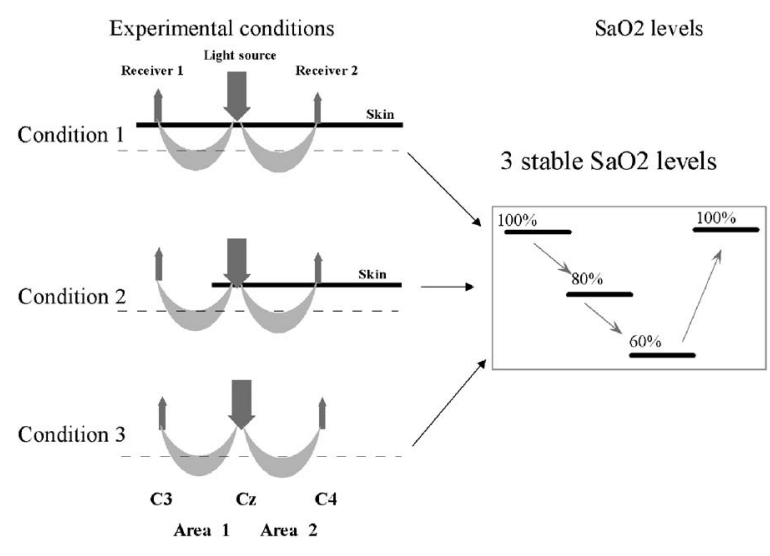

Fig. 2 Experimental design. Condition 1: all optodes on skin; condition 2: receiver 1 on skull, transmitting optode on skin; and condition 3: all optodes on skull. In all three conditions, the $\mathrm{SaO}_{2}$ was changed from 100 to 80 to 60 and back to $100 \%$. The measurements were repeated three times while the receiving optodes were simultaneously exchanged.

In our experiments, the distance between the transmitter and each receiver optode was $1.8 \mathrm{~cm}$. An estimate of the effective optical pathlength was incorporated by using an average pathlength factor of 4.2, which was estimated for infants. ${ }^{24,34}$

\subsection{Analysis and Statistics}

To estimate the effect of the arterial oxygen saturation changes at the different areas for the three skin conditions, a linear regression was performed of the simultaneously measured concentration changes with respect to the normoxia level. Thus, $\Delta c \mathrm{O}_{2} \mathrm{Hb}$ and $\Delta c \mathrm{HHb}$ were estimated for area 1 against area 2 for skin conditions 1 and 3. Taking this linear regression for skin condition 2 gives the effect of changing from both optodes on the skin to the condition of one optode on skull measurements.

To eliminate the eventual effect of the area on the effect of skin removal, the averaged difference in concentration change $(d \Delta)$ for each piglet and for each arterial oxygen saturation level, between areas 1 and 2 under skin condition 1, was subtracted from the results for skin conditions 2 and 3. The concentration changes of $c \mathrm{O}_{2} \mathrm{Hb}$ and $c \mathrm{HHb}$ were averaged over all identical skin conditions, arterial oxygen saturation levels, and over the animals. Also, the standard deviation and standard error of the mean were calculated. The interindividual spread of measured concentration changes was assessed in this way.

\section{Results}

The average optical density measured in our experiments was 6 to 7 OD. The reproducibility of repeated density measurements (intraindividual spread) was approximately 0.01 OD (standard deviation, SD), whereas the interindividual spread (between areas, between animals) was around 0.3 OD (SD). When expressed as variability of total hemoglobin concentration changes, these data are $1.5 \mu \mathrm{mol} / \mathrm{L}$ intra- and $4.2 \mu \mathrm{mol} / \mathrm{L}$ interindividual spread.

The optical density change for all three wavelengths between the conditions without and with skin when averaged
Table 1 Mean (SEM, standard error of the mean) concentration changes caused by arterial oxygen saturation changes from $\mathrm{SaO}_{2}$ $=100$ to $80 \%$ and from 100 to $60 \%$ level. Skin conditions are noted here as receiver $(R)$ and transmitter $(T)$ on the skin or the skull. The concentration differences $(\Delta c)$ were averaged over the repeated measurements at the different $\mathrm{SaO}_{2}$ levels and over the different animals $(n=3)$.

\begin{tabular}{|c|c|c|c|c|}
\hline \multirow{2}{*}{$\begin{array}{c}\text { Skin } \\
\text { condition } \\
R-T\end{array}$} & \multirow[b]{2}{*}{$\begin{array}{c}\Delta \mathrm{SaO}_{2} \\
{[\%]}\end{array}$} & \multirow{2}{*}{$\begin{array}{c}\Delta c \mathrm{O}_{2} \mathrm{Hb} \\
{[\mu \mathrm{mol} / \mathrm{L}]} \\
\operatorname{Mean}(S E M)\end{array}$} & \multirow{2}{*}{$\begin{array}{c}\Delta \mathrm{cHHb} \\
{[\mu \mathrm{mol} / \mathrm{L}]} \\
\operatorname{Mean}(S E M)\end{array}$} & \multirow{2}{*}{$\begin{array}{c}\Delta c \mathrm{cHb} \\
{[\mu \mathrm{mol} / \mathrm{L}]}\end{array}$} \\
\hline & & & & \\
\hline \multirow{2}{*}{$\begin{array}{l}\text { Skin-skin } \\
(n=27)\end{array}$} & 80 to 100 & $-18.9(1.4)$ & $21.6(1.4)$ & $2.7(1.0)$ \\
\hline & 60 to 100 & $-29.3(1.8)$ & $33.2(2.1)$ & $3.9(0.9)$ \\
\hline \multirow{2}{*}{$\begin{array}{l}\text { Skull-skin } \\
\quad(n=9)\end{array}$} & 80 to 100 & $-23.4(3.1)$ & $25.9(3.7)$ & $2.5(3.0)$ \\
\hline & 60 to 100 & $-39.0(4.4)$ & $43.9(4.6)$ & $4.9(3.2)$ \\
\hline \multirow{2}{*}{$\begin{array}{c}\text { Skull-skull } \\
(n=18)\end{array}$} & 80 to 100 & $-22.7(2.4)$ & $27.7(1.9)$ & $4.9(2.3)$ \\
\hline & 60 to 100 & $-32.0(5.2)$ & $43.9(2.5)$ & $4.8(3.2)$ \\
\hline
\end{tabular}

over the piglets appeared for all arterial oxygen saturation levels nearly equal: removal of one skin part (i.e., for skin condition 2 versus 1) gave an increased optical density change of $0.51 \mathrm{OD}(\mathrm{SD}=0.28$, SEM: 0.03, $N=93)$. Two measurements were excluded because the OXYMON ran out of range.

The mean values of the concentration changes relative to the $\mathrm{SaO}_{2}=100 \%$ level for the three skin conditions are presented together with the standard error of the mean (SEM) in Table 1 . When the skin was removed (skin conditions 2 and 3 ), an increased change in $c \mathrm{O}_{2} \mathrm{Hb}$ and $c \mathrm{HHb}$ was found compared to skin condition 1 ; the effect on the change in $c \mathrm{tHb}$ was nearly negligible.

The effect of skin removal on the concentration changes is shown in Table 2. Here, the difference between the concentration changes relative to $\mathrm{SaO}_{2}=100 \%$ was taken under skin condition 2 for area 1 minus area 2. Only simultaneous measurements are taken to avoid errors caused by differences in physiological condition. To eliminate the difference in area, the same was done for skin condition 1 (both with skin) and

Table 2 The Mean (SEM, $n=9$ ) concentration changes caused by removal of the skin. First, the change in concentration with respect to the $\mathrm{SaO}_{2}=100 \%$ level was calculated, then the difference between the simultaneous measurements at area $=1$ (receiver on skull) and area $=2$ (receiver on skin) under skin condition 2 was calculated. The data were corrected for the area and averaged over the repeated measurements $(n=3)$ at the different $\mathrm{Sa}_{\mathrm{O}_{2}}$ levels and over the different animals $(n=3)$.

\begin{tabular}{|c|c|c|c|}
\hline & $\begin{array}{l}d \Delta c \mathrm{O}_{2} \mathrm{Hb} \\
{[\mu \mathrm{mol} / \mathrm{L}]}\end{array}$ & $\begin{array}{c}d \Delta \mathrm{cHHb} \\
{[\mu \mathrm{mol} / \mathrm{L}]}\end{array}$ & $\begin{array}{c}d \Delta c+H b \\
{[\mu \mathrm{mol} / \mathrm{L}]}\end{array}$ \\
\hline $\begin{array}{c}\Delta \mathrm{SaO}_{2} \\
{[\%]}\end{array}$ & Mean (SEM) & Mean (SEM) & Mean (SEM) \\
\hline 80 to 100 & $-5.3(3.2)$ & $4.7(2.2)$ & $-0.6(4.5)$ \\
\hline 60 to 100 & $-7.2(3.5)$ & $6.1(2.6)$ & $-1.1(4.5)$ \\
\hline
\end{tabular}


the averages for each arterial oxygen saturation level and for each animal were subtracted from the result under skin condition 2. It appears that the observed increase in optical density following skin removal results in an apparent increase of both the $c \mathrm{O}_{2} \mathrm{Hb}$ and $c \mathrm{HHb}$ changes of approximately $23 \%$.

The effect of skin removal on the concentration changes is further illustrated in Fig. 3. In this picture, the concentration changes of $c \mathrm{O}_{2} \mathrm{Hb}$ and $c \mathrm{HHb}$ at $\mathrm{SaO}_{2}$ levels of 60 and $80 \%$ with respect to those obtained at the $\mathrm{SaO}_{2}=100 \%$ level obtained for area 1 ( $\mathrm{C} 3$ to $\mathrm{C} z$ ) are plotted versus those of area 2 ( $\mathrm{C} 4$ to $\mathrm{C} z$ ). We compared the different areas with both optodes on the skin [Fig. 3(a)] and both optodes on the skull [Fig. 3(b)]. The relation between concentrations as obtained for the left and right hemisphere is well described by a linear fit $\left(R^{2}=0.99\right.$ and 0.94$)$ with a slope of nearly one (1.03 and 0.99). This shows that the observations of the changes in $c \mathrm{O}_{2} \mathrm{Hb}$ and $c \mathrm{HHb}$ over both areas are nearly identical.

In Fig. 3(c) the effects of skin removal at one hemisphere are shown. Again, a high correlation is found $\left(R^{2}=0.89\right)$ but the slope constant equals 0.85 in this case. This implies that skin removal produces an (apparent) increase by $15 \%$ of concentration changes induced by changing the $\mathrm{SaO}_{2}$ level.

In Fig. 4 the concentration changes due to skin removal are plotted as the difference with respect to the $\mathrm{SaO}_{2} 100 \%$ level versus the $\mathrm{SaO}_{2}$ level. A practically linear relation is found between $\mathrm{SaO}_{2}$ and $c \mathrm{O}_{2} \mathrm{Hb}$ (decrease) and $c \mathrm{HHb}$ (increase). As was observed already in Table 2, the effect of skin removal on $c \mathrm{tHb}$ is practically negligible and independent of the $\mathrm{SaO}_{2}$ level.

\section{Discussion}

The observations in Sec. 4 show that the optical density increased for all wavelengths with a mean of $0.51 \mathrm{OD}$, for single optode skin removal. This corresponds to an increase of the light attenuation by a factor of 1.67. This OD increase is caused by changes in boundary conditions (skin removal and different light path through skull-CSF layer-brain tissue) and by changes in absorption. Many simulation studies about the influence of superficial layers have been done, ${ }^{16,17,35,36}$ but these concentrate on the effect of skull and CSF layer. To our knowledge these authors did not look exclusively at the influence of the skin. A finding of increased absorption similar to the one presented in Sec. 4 was published by Young et al. ${ }^{15}$ These authors found upon skin removal an increase of the overall attenuation by a factor of 0.5 , i.e., a density increase of 0.69 OD. They ascribed this apparent "attenuation" increase by the removal of light tunneling effects within the skin and in subcutaneous layers. The data presented in our study (i.e., $0.51 \mathrm{OD})$ are of the same order of magnitude.

In Table 1 it is shown that removal of the skin (under one or two optodes) yielded an increase in magnitude of the concentration changes of $\Delta c \mathrm{O}_{2} \mathrm{Hb}$ and $\Delta c \mathrm{HHb}$ (with respect to the $\mathrm{SaO}_{2}=100 \%$ level), and the $\Delta c \mathrm{tHb}$ remained nearly constant. The fact that the $\Delta c \mathrm{tHb}$ did not change shows that the $\mathrm{SaO}_{2}$ step from 100 to $60 \%$ did not cause a change in the blood content in the examined area.

The calculation of the absolute change of hemoglobin concentrations due to manipulation of the arterial oxygen saturation is done for identical optode positions and skin conditions. In this case, $R$ and other oxygenation-independent absorption
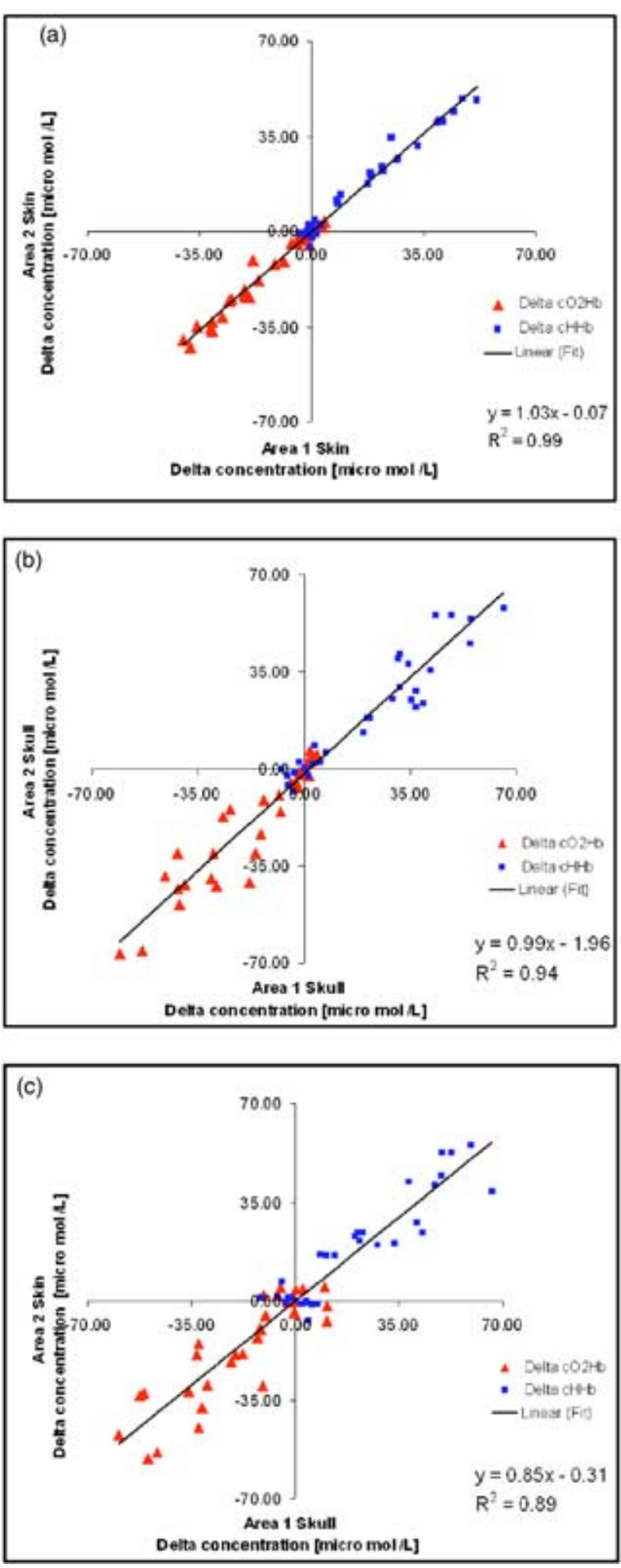

Fig. 3 Hemoglobin concentration changes due to changes of $\mathrm{SaO}_{2}$ level; simultaneously measured data from left hemisphere plotted versus those of right hemisphere. (a) Optodes of both hemispheres on intact skin (skin condition 1). (b) Optodes of both hemispheres on skull (skin condition 3). (c) Receiving optode over right hemisphere on skull, transmitting and receiving optode on the left hemisphere on skin (skin condition 2). The area correction was applied to skin conditions 2 and 3 by subtracting the left-right difference at skin condition $1(d \Delta)$ at each arterial oxygen saturation level and for each piglet. 


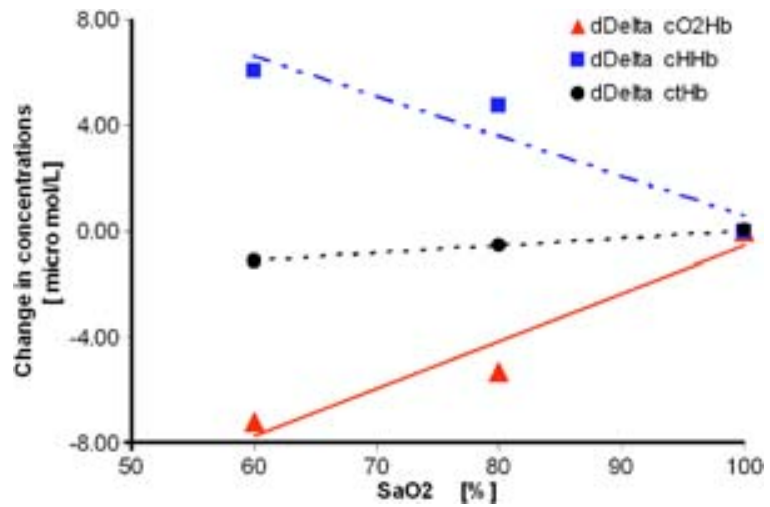

Fig. 4 The difference between receiver without and with skin (skin condition 2) of the concentration changes as a result of arterial oxygen saturation change from 100 to 80 and to $60 \%$. Concentrations were averaged over the repeated measurements and animals at each arterial oxygen saturation level.

terms cancel out in the equations [Eq. (3)]. Nevertheless, the effect of skin removal on DPF remains in the equation and this is actually being measured [Eq. (4)]. However, since a change of DPF cannot be estimated by cw-NIRS, it will be interpreted as an apparent change of concentration.

During hypoxia, the $\mathrm{PaCO}_{2}$ level was measured by arterial blood gas analysis and the variations were small (less than $5 \%$ ). There was no correlation found between $\mathrm{PaCO}_{2}$ and $\mathrm{SaO}_{2}$. Along the line of thought in the preceding paragraph, the present results are most probably due to an increase of the amount of light passing through the cortex of the brain, i.e., more tissue path containing hemoglobin due to a reduction of the tunneling effect, and therefore a higher absorption. In Eq. (5) a distinction was made between the DPF with and without skin. When the skin is removed, the optode distance stays constant but the effective light path, i.e., the DPF, might have changed. The light probably will go deeper into the brain tissue, or alternatively the tunneling effect might have changed. This will be translated into an apparent change in concentrations. The $d \Delta$ concentration effects might be caused by changes in the absorption and by changes in the optical pathlength, the latter of which is related to an increase in scattering and possible reduction of the tunneling effect. The DPF was in our calculations kept constant; therefore, the calculated concentration changes $d \Delta$ will be overestimated.

In Table 2 the difference between simultaneous measurements with the receiver on the skin and on the skull is taken (skin condition 2, i.e., left brain versus right brain). We see that the $d \Delta c \mathrm{O}_{2} \mathrm{Hb}$ decreases and the $d \Delta c \mathrm{HHb}$ increases when the arterial oxygen saturation decreases. This supports the assumption of an increased amount of blood in the increased light path when the skin is removed. The $d \Delta c \mathrm{tHb}$ remains nearly zero because $\Delta \mathrm{tHb}$ nearly did not change either.

In Table 1 we look at the effects of skin condition on the concentration changes caused by arterial saturation changes. We see that removal of one skin part gives a large difference in concentration changes. But removal of two skin parts makes nearly no additional difference on the concentration changes. This might be explained by the change in tunneling effect. Removing one skin part may stop the tunneling at the skin-skull layer, so the second skin removal will not change the tunneling but it will only change the light path through the tissue.

From Tables 1 and 2 we see that removal of the skin gave an apparent increase of the concentration changes of $23 \%$, which is nearly equal to the result of $15 \%$ shown in Fig. 3(c). This implies that the oxygenation changes due to changes of (physiological) conditions, which are measured with NIRS, can have 15 to $23 \%$ influence of the presence of the skin.

The present study was made with a relatively small distance between transmitting and receiving optodes. Since it is known that enlarging this distance yields less influence of skin on concentration measurements, such an enlargement would be the first choice for improvement of the NIRS measurement of cerebral oxygenation. However, at the same time, precision decreases due to enhanced light attenuation related to the enlarged light path. This induces a need for improvement of the signal-to-noise ratio of the density measurements.

A second possibility would be to use experimental data to correct the concentration changes measured with undisturbed, i.e., intact skin. The magnitude of this correction might, however, be species dependent. Nevertheless, the present study shows that such a correction would surely not be trivial, nor the result of it negligible.

We conclude that the skin influences regional cerebral oxygenation measurements. Moreover, we hypothesize that after removal of the skin, the estimated concentration changes of $c \mathrm{O}_{2} \mathrm{Hb}$ and $c \mathrm{HHb}$ due to arterial saturation changes are dominated by oxygenation changes in the brain tissue, while assuming that in a stable condition of the animals, the influence of the CSF layer and the skull is oxygen independent.

\section{Acknowledgments}

This work was financed by the Technology Branch of the Netherlands' Organization for Scientific Research (STW, project TTN.4661). We thank the staff of the Animal Laboratory for their assistance with animal preparation.

\section{References}

1. F. F. Jobsis, "Noninvasive, infrared monitoring of cerebral and myocardial oxygen sufficiency and circulatory parameters," Science 198, 1264-1267 (1977).

2. M. C. van Beekvelt, W. N. Colier, R. A. Wevers, and B. G. van Engelen, "Performance of near-infrared spectroscopy in measuring local $\mathrm{O}(2)$ consumption and blood flow in skeletal muscle," J. Appl. Physiol. 90, 511-519 (2001).

3. M. Ferrari, E. Zanette, I. Giannini, G. Sideri, C. Fieschi, and A Carpi, "Effects of carotid artery compression test on regional cerebral blood volume, hemoglobin oxygen saturation and cytochrome-Coxidase redox level in cerebrovascular patients," Adv. Exp. Med. Biol. 200, 213-221 (1986).

4. N. B. Hampson, E. M. Camporesi, B. W. Stolp, R. E. Moon, J. E. Shook, J. A. Griebel, and C. A. Piantadosi, "Cerebral oxygen availability by NIR spectroscopy during transient hypoxia in humans," $J$. Appl. Physiol. 69, 907-913 (1990).

5. D. N. Harris, F. M. Cowans, D. A. Wertheim, and S. Hamid, NIRS in Adults-Effects of Increasing Optode Separation, Plenum Press, New York (1994).

6. K. D. Liem, J. C. Hopman, L. A. Kollee, and B. Oeseburg, "Effects of repeated indomethacin administration on cerebral oxygenation and haemodynamics in preterm infants: combined near infrared spectrophotometry and Doppler ultrasound study," Eur. J. Pediatr. 153, 504509 (1994).

7. K. D. Liem, J. C. Hopman, B. Oeseburg, A. F. de Haan, and L. A. Kollee, "The effect of blood transfusion and haemodilution on cere- 
bral oxygenation and haemodynamics in newborn infants investigated by near infrared spectrophotometry," Eur. J. Pediatr. 156, 305310 (1997).

8. J. S. Wyatt, M. Cope, D. T. Delpy, C. E. Richardson, A. D. Edwards, S. Wray, and E. O. Reynolds, "Quantitation of cerebral blood volume in human infants by near-infrared spectroscopy," J. Appl. Physiol. 68, 1086-1091 (1990).

9. H. U. Bucher, A. D. Edwards, A. E. Lipp, and G. Duc, "Comparison between near infrared spectroscopy and 133Xenon clearance for estimation of cerebral blood flow in critically ill preterm infants," $\mathrm{Pe}$ diatr. Res. 33, 56-60 (1993).

10. L. Skov, O. Pryds, and G. Greisen, "Estimating cerebral blood flow in newborn infants: comparison of near infrared spectroscopy and 133Xe clearance," Pediatr. Res. 30, 570-573 (1991).

11. P. Hopton, T. S. Walsh, and A. Lee, "Measurement of cerebral blood volume using near-infrared spectroscopy and indocyanine green elimination," J. Appl. Physiol. 87, 1981-1987 (1999).

12. E. Keller, A. Nadler, H. Alkadhi, S. S. Kollias, Y. Yonekawa, and P. Niederer, "Noninvasive measurement of regional cerebral blood flow and regional cerebral blood volume by near-infrared spectroscopy and indocyanine green dye dilution," Neuroimage 20, 828-839 (2003).

13. M. Hiraoka, M. Firbank, M. Essenpreis, M. Cope, S. R. Arridge, P. van der Zee, and D. T. Delpy, "A Monte Carlo investigation of optical pathlength in inhomogeneous tissue and its application to nearinfrared spectroscopy," Phys. Med. Biol. 38, 1859-1876 (1993).

14. E. Okada, M. Firbank, and D. T. Delpy, "The effect of overlying tissue on the spatial sensitivity profile of near-infrared spectroscopy," Phys. Med. Biol. 40, 2093-2108 (1995)

15. A. E. Young, T. J. Germon, N. J. Barnett, A. R. Manara, and R. J. Nelson, "Behaviour of near-infrared light in the adult human head: implications for clinical near-infrared spectroscopy," Br. J. Anaesth. 84, 38-42 (2000).

16. E. Okada, M. Firbank, M. Schweiger, S. R. Arridge, M. Cope, and D. T. Delpy, "Theoretical and experimental investigation of nearinfrared light propagation in a model of the adult head," Appl. Opt. 36, 21-31 (1997).

17. E. Okada and D. T. Delpy, "Near-infrared light propagation in an adult head model. II. Effect of superficial tissue thickness on the sensitivity of the near-infrared spectroscopy signal," Appl. Opt. $\mathbf{4 2}$, 2915-2922 (2003).

18. P. Smielewski, P. Kirkpatrick, P. Minhas, J. D. Pickard, and M. Czosnyka, "Can cerebrovascular reactivity be measured with near-infrared spectroscopy?" Stroke 26, 2285-2292 (1995).

19. P. Smielewski, M. Czosnyka, J. D. Pickard, and P. Kirkpatrick, "Clinical evaluation of near-infrared spectroscopy for testing cerebrovascular reactivity in patients with carotid artery disease," Stroke 28, 331-338 (1997).

20. J. H. G. M. Klaessens, S. H. G. van Os, J. C. Hopman, K. D. Liem, M. van de Bor, and J. M. Thijssen, "In vivo measurements of the influence of the skin on cerebral oxygenation changes measured with near infrared spectrophotometry (NIRS)," Proc. SPIE 5318, 85-93 (2004).

21. F. Faris, M. Thorniley, Y. Wickramasinghe, R. Houston, P. Rolfe, N. Livera, and A. Spencer, "Noninvasive in vivo near-infrared optical measurement of the penetration depth in the neonatal head," Clin. Phys. Physiol. Meas. 12, 353-358 (1991).

22. M. S. Thorniley, L. N. Livera, Y. A. Wickramasinghe, S. A. Spencer, and P. Rolfe, "The non-invasive monitoring of cerebral tissue oxygenation," Adv. Exp. Med. Biol. 277, 323-334 (1990).

23. D. T. Delpy, M. Cope, P. van der Zee, S. Arridge, S. Wray, and J. Wyatt, "Estimation of optical pathlength through tissue from direct time of flight measurement," Phys. Med. Biol. 33, 1433-1442 (1988).

24. S. Wray, M. Cope, D. T. Delpy, J. S. Wyatt, and E. O. Reynolds, "Characterization of the near infrared absorption spectra of cytochrome aa3 and haemoglobin for the non-invasive monitoring of cerebral oxygenation," Biochim. Biophys. Acta 933, 184-192 (1988).

25. J. S. Wyatt, M. Cope, D. T. Delpy, P. van der Zee, S. Arridge, A. D. Edwards, and E. O. Reynolds, "Measurement of optical path length for cerebral near-infrared spectroscopy in newborn infants," Dev. Neurosci. (Basel, Switz.) 12, 140-144 (1990).

26. Y. Wickramasinghe and P. Rolf, "Modified NIR coefficients taking into account the wavelength dependence of the optical path length," in Newsletter EC Concerted Action Near Infrared Spectroscopy and Imaging of Biological Tissue, J. Bancraft Ed., pp. 5 (1993).

27. Y. Hasegawa, Y. Yamada, M. Tamura, and Y. Nomura, "Monte Carlo simulations of light transmission through living tissues," Appl. Opt. 30, 4515-4520 (1991)

28. J. H. G. M. Klaessens, J. M. Thijssen, J. C. Hopman, and K. D. Liem, "Experimental verification of conditions for near infrared spectroscopy (NIRS)," Technol. Health Care 11, 53-60 (2003).

29. M. S. Patterson, B. C. Wilson, and D. R. Wyman, "The propagation op optical radiation in tissue; 1 . Models of radiation transport and their application," Lasers Med. Sci. 6, 155-168 (1991).

30. T. N. Raju, "Some animal models for the study of perinatal asphyxia," Biol. Neonate 62, 202-214 (1992).

31. M. C. van Wijk, J. H. Klaessens, J. C. Hopman, K. D. Liem, and J. M. Thijssen, "Assessment of local changes of cerebral perfusion and blood concentration by ultrasound harmonic B-mode contrast measurement in piglet," Ultrasound Med. Biol. 29, 1253-1260 (2003).

32. M. C. van der Sluijs, W. N. J. M. Colier, R. J. Houston, and B. Oeseburg, "New and highly sensitive continuous-wave near-infrared spectrophotometer with multiple detectors," Proc. SPIE 3194, 63-72 (1997).

33. K. D. Liem, B. Oeseburg, and J. C. Hopman, "Method for the fixation of optrodes in near-infra-red spectrophotometry," Med. Biol. Eng. Comput. 30, 120-121 (1992).

34. P. van der Zee, M. Cope, S. R. Arridge, M. Essenpreis, L. A. Potter, A. D. Edwards, J. S. Wyatt, D. C. McCormick, S. C. Roth, and E. O Reynolds, "Experimentally measured optical pathlengths for the adult head, calf and forearm and the head of the newborn infant as a function of inter optode spacing," Adv. Exp. Med. Biol. 316, 143-153 (1992)

35. Y. Fukui, Y. Ajichi, and E. Okada, "Monte Carlo prediction of nearinfrared light propagation in realistic adult and neonatal head models," Appl. Opt. 42, 2881-2887 (2003).

36. E. Okada and D. T. Delpy, "Near-infrared light propagation in an adult head model. I. Modeling of low-level scattering in the cerebrospinal fluid layer," Appl. Opt. 42, 2906-2914 (2003). 